Ensino, Saúde e Ambiente - V9 (3), pp. 171-188, Dez. 2016

\title{
ASPECTOS DA NATUREZA DA CIÊNCIA NOS TEXTOS SOBRE EVOLUÇÃO BIOLÓGICA DA REVISTA SCIENTIFIC AMERICAN BRASIL
}

\author{
ASPECTS OF THE NATURE OF SCIENCE IN TEXTS ON BIOLOGICAL \\ EVOLUTION IN SCIENTIFIC AMERICAN BRAZIL \\ Marcelo Borges Rocha ${ }^{1}$, Marana Vargas ${ }^{2}$ \\ ${ }^{1}$ Centro Federal de Educação Tecnológica Celso Suckow da Fonseca/Departamento de Pós- \\ graduação/rochamarcelo36@yahoo.com.br \\ ${ }^{2}$ Centro Federal de Educação Tecnológica Celso Suckow da Fonseca/Departamento de Pós-graduação/ \\ mvargas@hotmail.com
}

\section{RESUMO}

Este estudo realizou uma análise de textos de Divulgação Científica presentes na revista Scientific American Brasil sobre o tema Evolução Biológica, utilizando-se deste para considerar as perspectivas sobre Natureza da Ciência. As argumentações se basearam nas ideias de Natureza da Ciência que estavam implícita ou explicitamente apresentadas e de que forma estas podem ser capazes de influenciar as concepções dos leitores e leválos a uma distorção da imagem da Ciência. A partir desta análise, concluiu-se que as pesquisas brasileiras apresentam baixa representatividade nesta revista e há alguns comprometimentos quanto às visões de Natureza da Ciência, tais como: as distorções quanto às visões serem ahistóricas, lineares, o conhecimento construído a partir de 'descobertas' realizadas por 'gênios isolados' e os mecanismos evolutivos mais frequentes são explicados pela seleção natural, com noções predominantes de teleologia num contexto de mera citação.

Palavras-chave: Divulgação Científica. Natureza da Ciência. Evolução Biológica.

\begin{abstract}
This study conducted an analysis of texts in science communication present in Scientific American Brazil about Biological Evolution, using this to consider the perspectives of Nature of Science. The arguments were based on the ideas of Nature of Science that were implicitly or explicitly presented and how they may be able to influence the views of readers and get them to a distorted view of science. From this analysis, it was concluded that the Brazilian researches have low representation in this magazine and there are some compromises regarding visions of Nature of Science, such as distortions about the visions being ahistorical, linear, knowledge built from 'discoveries 'made by' isolated geniuses' and more frequent evolutionary mechanisms are explained by natural selection, with prevailing notions of teleology in the context of mere citation.
\end{abstract}

Keywords: Science Communication. Nature of Science. Biological Evolution. 


\section{Ensino, Saúde e Ambiente - V9 (3), pp. 171-188, Dez. 2016}

\section{INTRODUÇÃO}

As visões sobre Natureza da Ciência $(\mathrm{NdC})$ presentes na maioria dos textos de Divulgação Científica (DC) são construídas de acordo com as influências da tríade Ciência-Tecnologia-Sociedade (CTS) que cada autor pode ter, destacando o equilíbrio dessas partes ou a tendência da predominância de qualquer que seja.

Uma maneira de demonstrar visões não deformadas da $\mathrm{NdC}$ ou de corrigir tais visões está na instrumentalização da Alfabetização Científica pela DC, no âmbito formal ou não formal de ensino. Isso porque, uma melhor compreensão da $\mathrm{NdC}$ permite tomar decisões mais refletidas sobre questões tecno-científicas de interesse social, o que contribuiria para tornar mais efetiva a participação como cidadão (ACEVEDO et al, 2005).

Ainda, segundo Acevedo et al (2005, p. 2) "pensa-se que um dos principais objetivos do ensino das ciências é a aprendizagem da NdC", mas a aprendizagem da NdC pode estar também presente no ensino não formal, como nos meios de divulgação científica em seus mais diversos canais. De qualquer maneira, a compreensão sobre a NdC leva a melhor compreensão das interferências sofridas e aplicadas pela construção e divulgação dos conhecimentos científicos produzidos na relação estabelecida entre a CTS.

Quando se pensa então, no tipo de $\mathrm{NdC}$ que se pretende apresentar, pensa-se também em que tipo de Alfabetização Científica se tem realizado, pois,

defende-se como adequado para a educação científica básica, por exemplo, a crítica ao empirismo ingênuo, a necessidade de apresentar a ciência como uma construção humana, a impossibilidade de observação neutra dos fenômenos naturais, dentre outras (FORATO et al, 2011, p. 33).

Apesar dessa defesa em relação ao tipo de Ciência que se quer apresentar durante o processo de Alfabetização Científica e a visão de $\mathrm{NdC}$ que se pretende estruturar, "reporta-se, pois, à ideia de ciência como um corpo de conhecimentos em constantes transformações por meio de processo de aquisição e análise de dados, síntese e decodificação de resultados que originam os saberes" (SASSERON E CARVALHO, 2011, p. 75). O que pode ser benéfico inicialmente, pois mostra uma ciência em desenvolvimento e processo construtivo, pode se perder caso não demonstre as relações CTS neste processo. Segundo Solomon (1988 apud SANTOS, 2007, p. 484),

discute-se que, ao apresentar-se o caráter provisório e incerto das teorias científicas, os alunos podem avaliar as aplicações da ciência, levando em conta as opiniões controvertidas dos especialistas. Ao contrário, com uma 
visão de ciência como algo absolutamente verdadeiro e acabado, os alunos terão dificuldade de aceitar a possibilidade de duas ou mais alternativas para resolver um determinado problema.

Assim, a necessidade de se produzir textos de DC coerentes com a NdC que se quer abordar, como uma forma de Alfabetização Científica que leve ao pensamento estruturado e crítico por parte dos cidadãos é um desafio, pois a linguagem, a formação do autor, sua carga sociocultural e suas intencionalidades fazem parte dessa produção. Esta, posteriormente, não tem como ser controlada por parte do leitor, a menos que este tenha sido alfabetizado cientificamente e compreenda o conteúdo do texto lido e consiga estabelecer as relações mais concretas da tríade CTS.

Entretanto, na educação formal

É comum os currículos de Ciências estarem demasiado centrados nos conteúdos conceptuais e não processuais, tendo como referência a lógica interna da própria ciência e, assim, esquecem a formação que exige a construção científica. Tal justifica-se pela complexidade da $\mathrm{NdC}$ e pelo facto de que os próprios filósofos e sociólogos da ciência terem, por vezes, muitas divergências sobre os princípios básicos desta (PRAIA et al, 2007, p. 146).

Por isso, o processo de Alfabetização Científica para um aprofundamento dos cidadãos nas relações CTS, por meio da Divulgação Científica no âmbito formal ou não formal de ensino permite a todos, e não somente àqueles que pretendem uma carreira científica, as visões mais adequadas da $\mathrm{NdC}$ que se busca disseminar e que levarão às melhores tomadas de posição frente às adversidades e controvérsias que possam se apresentar.

Segundo Bybee (1997 apud Praia et al, 2007, p. 146), "uma adequada alfabetização exige, precisamente, a imersão dos estudantes numa cultura científica. Uma imersão que deve ir mais além da aquisição de "pontos de vista sobre a $\mathrm{NdC}$ ".

Se assim for, então teremos um ciclo vicioso, onde a NdC é complexa para ser foco da alfabetização científica que se deseja e que o ensino formal está fechado para inserções de textos de DC, por exemplo para ampliação dos conhecimentos. Nesse caso, mantem-se as "visões empobrecidas e distorcidas que geram o desinteresse, quando não mesmo o abandono, de muitos estudantes, e se convertem num obstáculo para a aprendizagem" (PRAIA et al, 2007, p. 147). 


\title{
A relevância da Evolução Biológica nos estudos sobre a Natureza da Ciência e o Ensino de Ciências
} considerada

A Evolução Biológica à luz da NdC e da História e Filosofia da Ciência é

A teoria mais unificadora dentre todas as teorias biológicas. Antes dela, as diversas áreas das ciências biológicas eram independentes, reunidas fragmentariamente na chamada História Natural. Só a partir desta surgiu a Biologia com o seu estatuto e paradigmas unificadores como ciência (ALMEIDA E DA ROCHA FALCÃO, 2005, p. 17).

Esta afirmativa encontra respaldo nas palavras de Theodosius Dobzhansky, notável geneticista e biólogo evolutivo ucraniano, no célebre artigo 'Nada em Biologia faz sentido se não for à luz da Evolução' (CERQUEIRA, 2009). Além disso, este assunto apresenta muitas controvérsias no ensino de Ciências e Biologia, em todos os seus níveis, seja por parte dos docentes ou dos discentes.

De fato, o conceito de evolução mostra-se permeado por obstáculos epistemológicos, de fundo ideológico, filosófico e teológico, o que torna sua abordagem em contexto de sala de aula particularmente difícil, tanto no ensino, por parte dos professores, quanto na aprendizagem, por parte dos alunos (ALMEIDA E DA ROCHA FALCÃO, 2005, p. 17).

Até porque, o processo de aprendizagem requer mudanças de paradigmas muitas vezes permeados por visões particulares dos alunos e professores, o chamado 'senso comum', que seria anterior ao período de AC. Assim,

\begin{abstract}
Aprender ciências envolve um processo de socialização das práticas da comunidade científica e de suas formas particulares de pensar e de ver o mundo, em última análise, um processo de 'enculturação'. Sem as representações simbólicas próprias da cultura científica, o estudante muitas vezes se mostra incapaz de perceber, nos fenômenos, aquilo que o professor deseja que ele perceba (MORTIMER, 1996, p. 24).
\end{abstract}

Nesse processo de 'enculturação' científica, a mudança conceitual de senso comum dos alunos provém do ensino formal ou da AC advinda da instrumentalização oferecida pela DC. Desta forma,

O ensino deve visar uma mudança do perfil conceitual dos alunos por enriquecimento do espectro de ideias disponíveis para a compreensão dos problemas. Além de introduzir as novas ideias compatíveis com a visão científica, clássica e/ou moderna, deve-se auxiliar o aluno a reconhecer os contextos nos quais é oportuno utilizar cada tipo de ideia, seja ela científica ou não (VILLANI, 2001, p. 175).

Visto como um dos paradigmas no campo das teorias evolutivas a serem modificados pelos alunos e, descrito constantemente, em muitos livros didáticos como teorias opostas, as concepções do inglês Charles Darwin e do francês Jean-Baptiste Lamarck sobre a evolução dos seres vivos serão vistas em seu contexto de produção 
formativa. Isto nos remete à Natureza da Ciência em seu ponto mais bruto que é a forma do pensamento da sociedade sobre a Ciência que está sendo construída.

Diante deste cenário, o objetivo deste estudo foi analisar textos de Divulgação Científica produzidos pela revista Scientific American Brasil no que diz respeito às características e visões da Natureza da Ciência à luz do tema Evolução Biológica.

\section{METODOLOGIA}

A revista Scientific American Brasil foi escolhida por ter um histórico dentro da Divulgação Científica, já que sua primeira versão mundial foi lançada em 28 de abril de 1845 era voltada a aspectos econômicos da Ciência e da Tecnologia, destinando-se, em especial, a um público de grandes industriais, comerciantes e fazendeiros (MACEDO, 2002). Segundo a Associação Brasileira de Imprensa, a maioria das reportagens é escrita por pesquisadores. O nível dos assuntos abordados é denso, entretanto a revista se propõe a ser para os leitores em geral.

O corpus documental desta pesquisa é composto por textos selecionados no site da revista a partir de uma busca utilizando-se como palavra-chave Evolução Biológica. A partir de então, realizou-se a leitura dos resumos de todos os textos encontrados para que fossem selecionados os que tivessem como viés a palavra-chave em seu eixo principal ou secundário.

Desde o início da publicação da versão brasileira da revista em 2002 até o ano de 2011, obteve-se um total de 40 textos dentro da temática investigada e, para análise, foram escolhidos os últimos cinco anos (2007 a 2011) por estes apresentarem maior representatividade (24 textos para análise). Para facilitar a análise foram criados códigos para os textos conforme o ano de publicação e ordem de aparição dentro do ano pesquisado, sendo conferidos, por exemplo, os códigos 2007_1, 2007_2, 2008_1 e assim por diante.

Para a análise dos dados coletados, utilizou-se a Análise de Conteúdo (BARDIN, 1977). Com esta metodologia, pretende-se inferir conhecimentos relativos às condições de produção com base em indicadores quantitativos ou qualitativos, com o objetivo de responder a duas questões. A primeira questão é "o que conduziu um determinado enunciado?", sendo que este aspecto se refere às causas ou antecedentes da mensagem. A segunda questão é "quais as consequências de um determinado enunciado pode provocar?", referindo-se aos possíveis efeitos da mensagem (BARDIN, 1977). 


\section{Ensino, Saúde e Ambiente - V9 (3), pp. 171-188, Dez. 2016}

Sendo assim, a Análise de Conteúdo compreende três etapas básicas. São elas: 1) pré-análise - "etapa e organização e sistematização do material e ideias iniciais";

2) exploração do material e tratamento de resultados - "exploração do material ocorre como consequência da pré-análise e consiste na administração sistemática das decisões tomadas anteriormente";

3) interferência e interpretação dos resultados - "Os resultados brutos são tratados de forma a se tornarem significativos e válidos" (GOMES, 1999, p. 75 e 76).

A partir e durante o percurso dessas etapas, foram estabelecidas categorias $a$ priori e/ou a posteriori para uma análise mais coerente entre os textos pesquisados. Geralmente as categorias são empregadas para se estabelecer classificações. Nesse sentido, trabalhar com elas significa agrupar elementos, ideias ou expressões em torno de um conceito capaz de abranger tudo isso (GOMES, 1999).

A Análise de Conteúdo, enquanto instrumento metodológico permite a criação de categorias e possíveis comparações entre os textos, indicando evidências que admitam uma inferência, não somente na mensagem ali contida, mas interpretações acerca dos resultados obtidos. E assim, esta se justifica porque "frequentemente utiliza variáveis da mídia, isto é aqueles aspectos do conteúdo que são únicos e característicos do meio utilizado" (EPSTEIN, 2002, p. 18).

As categorias foram estabelecidas durante a análise a posteriori dos textos, apoiando-se nos objetivos da pesquisa, bem como a priori nos trabalhos de Forato et al (2011), para as possibilidades de visões acerca da Natureza da Ciência.

As categorias que emergiram nas pesquisas e análises dos textos são representadas a seguir:

$\left.1^{a}\right)$ Concepções acerca da Natureza da Ciência em sua abordagem histórica e da elaboração do conhecimento científico como processo produtivo, se não linear e com ideias de melhorias/progresso;

$2^{a}$ ) Trabalho de produção envolvendo diversos atores para a construção de conceitos e não de gênios isolados;

$3^{a}$ ) Visões sobre a falibilidade da Ciência e não o modelo de 'verdades absolutas'. 


\section{RESULTADOS E DISCUSSÃO}

\section{Sobre a autoria e países de origem dos textos publicados}

Dos 24 textos analisados, somente seis deles (25\%) apresentaram autoria de pesquisadores brasileiros que atuam em instituições de pesquisa e ensino no Brasil. Nos demais temos: 11 textos de pesquisadores que atuam em instituições de pesquisa e ensino nos Estados Unidos, correspondentes a 45,8\% do total; 3 textos de pesquisadores que atuam em instituições de pesquisa e ensino na Inglaterra, correspondentes a 12,5\% do total; 1 texto de pesquisadores que atuam em instituições de pesquisa e ensino na Itália, correspondentes a $4,2 \%$ do total e 1 texto de pesquisadores que atuam em instituições de pesquisa e ensino na Austrália, correspondentes a 4,2\% do total. Sendo que, $8,3 \%$, ou seja, 2 textos não apresentam autoria. Diante deste resultado, percebe-se a baixa frequência de publicações e autores brasileiros na revista Scientific American Brasil.

De acordo com Petian et al (2006, p. 09),

\footnotetext{
O espaço reservado para divulgar acontecimentos relevantes relacionados à ciência desenvolvida no Brasil não passa de $20 \%$ do total da publicação (...) o número de fontes internacionais é aproximadamente 10 vezes maior que o número de fontes nacionais consultadas (...) no perfil editorial da revista, o país mais citado é os Estados Unidos. Os países da Europa vêm em seguida em número de citações.
}

Os dados apresentados por eles corroboram os resultados de nossa pesquisa, uma vez que a representatividade de publicações brasileiras é baixa e é dado maior destaque a fontes de pesquisas norte-americanas.

Ainda, "foi observado que, por se dedicar mais à divulgação das grandes descobertas científicas, a Scientific American Brasil busca suas fontes nos países onde há mais investimento em pesquisa e mais resultados conclusivos" (PETIAN et al, 2006, p. 08).

Além disso, "parte significativa dos artigos sobre ciência que são publicados é constituída de traduções de textos comprados ou disponibilizados de jornais ou revistas do exterior" (MOREIRA E MASSARANI, 2002, p. 63). Mais uma vez, valorizam-se as pesquisas internacionais e subestima-se, de certa forma, a Ciência produzida no Brasil. Mas esta valorização estrangeira ou essa menor visibilidade ao que é de origem brasileira assume uma postura quase histórica em nosso país e se encontra enraizada no pensamento popular. 


\section{Ensino, Saúde e Ambiente - V9 (3), pp. 171-188, Dez. 2016}

Segundo Izquierdo (2005) quando as pessoas lêem ou quando alguém lhes apresenta alguma notícia científica, as pessoas acham que estamos nos referindo a algum país estrangeiro. $\mathrm{O}$ autor ainda realizou uma pesquisa entre funcionários e alunos de pós-graduação de duas universidades brasileiras e os questionou sobre os países que apresentaram pesquisas de ponta nos últimos seis meses e os países citados foram: EUA, Japão, China, Argentina e Rússia. Esta nem sequer é a ordem exata ou os países que mais produzem tais pesquisas.

Izquierdo aponta ainda, que na América Latina, o Brasil está à frente da Argentina em termos de publicações, mas que prossegue a "crença generalizada de que 'ciência é coisa de primeiro mundo' ou, pelo menos, alheia ao país. Ignora-se ou não é levada a sério, a ciência feita no Brasil" (IZQUIERDO, 2005, p. 114).

Neste ponto nos voltamos para as motivações e ideais, tanto da Divulgação Científica (DC) quanto da Alfabetização Científica (AC) de modo a relacionar estas visões sobre a produção e as publicações da ciência brasileira vista pelos leitores e consumidores destas informações.

Sabe-se que a DC possui diversos objetivos e alguns deles complementam nossa argumentação. Segundo Albagli (1996, p. 02), existem os objetivos educacionais, cívico e de motivação popular para a DC. Dentro dos objetivos educacionais se destaca “a ampliação do conhecimento e da compreensão do público leigo a respeito do processo científico e sua lógica”. Já no objetivo para motivação popular, relacionada à $\mathrm{AC}$, ele diz que esta se inter-relaciona com a

ampliação da possibilidade e da qualidade de participação da sociedade na formulação de políticas públicas e na escolha de opções tecnológicas (...). Trata-se de transmitir informação científica que instrumentalize os atores a intervir melhor no processo decisório (ALBAGLI, 1996, p. 02).

Deste modo, identifica-se a necessidade de serem divulgadas as informações produzidas pelos pesquisadores brasileiros e que esta população esteja $\mathrm{AC}$, para que assim, se inteirem e revertam seus conceitos iniciais sobre a ciência que se produz aqui.

Primeiro, devemos fazer que os brasileiros leiam mais. Alfabetizar mais profundamente e melhor, hoje, $80 \%$ dos brasileiros são alfabetizados, mas deles, só 30\% leem jornais ocasional ou diariamente, e $80 \%$ jamais leem ou lerão um livro. Ou seja, atualmente, $20 \%$ da população não lê nada, $56 \%$ lêem pouco, e $84 \%$ não leem livros. Só $16 \%$ da população está realmente em condições de ler sobre ciência ou qualquer outro assunto. Sem público-alvo, não há campanha que funcione... (IZQUIERDO, 2005, p. 116).

Posteriormente a esta alfabetização mais efetiva da população, com programas de incentivos públicos por parte da escola e de outros meios, se faz necessário também, 
buscar uma mudança de pensamento sobre o que é e a importância da DC para os pesquisadores brasileiros.

Nos últimos anos, embora tenha havido um interesse crescente no meio acadêmico relativo às atividades de extensão ligadas à divulgação científica, o quadro geral ainda é frágil. Tais atividades ainda são consideradas marginais e, na maioria das instituições, não influenciam na avaliação de professores e pesquisadores (MOREIRA E MASSARANI, 2003, p. 64).

Além disso, muitas vezes a linguagem científica se distancia do público leitor, que por sua vez, enxerga na ciência um tipo de conhecimento intangível. Para Albagli (1996, p.03),

formulado desse modo, o problema leva toda a atenção da pesquisa crítica para a sociedade e a mídia. Os únicos problemas no âmbito da ciência estão relacionados a induzir os cientistas a comunicarem-se mais clara e interessantemente em termos leigos.

Portanto, deve-se ter em mente que os fatores para a baixa representatividade de autores brasileiros em revistas como a Scientific American Brasil apresentam várias e diferentes motivações. Desde aquelas relacionadas ao corpo editorial, passando pela forma histórica que a ciência produzida no Brasil é vista e valorizada pela sociedade e, finalizando com os porquês desta visão.

Estas podem ter suas justificativas, desde a forma em que a linguagem está representada nos textos escritos pelos cientistas, perpassando pelas políticas e práticas de AC e até mesmo, a importância dada pelos próprios pesquisadores para a divulgação de seus estudos que não seja apenas aos seus pares ou em revistas de maior visibilidade internacional.

\section{As concepções sobre Natureza da Ciência}

As concepções e perspectivas acerca da Natureza da Ciência (NdC) presentes nos discursos de DC tendem a moldar ou, minimamente, influenciar a visão que o leitor pode ter em resposta ao tipo de NdC que se apresente nos textos (PRAIA et al, 2007). Além disso, estas concepções não são aleatórias e permeiam, em muitos casos, a formação acadêmica do divulgador, suas interações com outros pesquisadores e outras fontes de estudo, além de sua experiência pessoal de vida. Já que estas concepções geralmente vão de encontro a uma proximidade das crenças do divulgador sobre o item analisado, vemos no quadro 1 alguns exemplos sobre tais características encontradas em alguns dos textos analisados. 
Quadro 1. Concepções de Natureza da Ciência

\begin{tabular}{|c|c|}
\hline Textos & Concepções sobre a Natureza da Ciência \\
\hline 2007_3 & $\begin{array}{l}\text { O texto foi escrito por três pesquisadores que indicaram um histórico na produção do conhecimento } \\
\text { científico abordado no texto. E não somente isto, mas também, buscaram informações em outros } \\
\text { grupos de pesquisas para corroborarem e justificarem o tema de estudo. Não traz a ideia de verdades } \\
\text { absolutas, apesar de não indicar contradições efetivas. }\end{array}$ \\
\hline 2007_6 & $\begin{array}{l}\text { O texto foi escrito por um jornalista sobre o trabalho de uma pesquisadora. Em parte se ocupa em } \\
\text { demostrar suas constatações e em outra, seu trabalho em equipe. Traz informações sobre a construção } \\
\text { dos conceitos por outros autores, porém, não faz uma referência histórica para tal processo. } \\
\text { Demonstra também verdades absolutas e não falíveis. }\end{array}$ \\
\hline 2011_3 & $\begin{array}{l}\text { A reportagem foi escrita por uma pesquisadora norte-americana. A pesquisa caracteriza seu processo de } \\
\text { construção histórica e relaciona seus resultados a outros grupos de pesquisadores. Apresenta a } \\
\text { metodologia da pesquisa bem descrita e uma tendência à neutralidade, mesmo expondo os pontos } \\
\text { falhos. Alguns resultados são apresentados como 'descobertas intrigantes' ou 'não esperadas'. }\end{array}$ \\
\hline 2011_4 & $\begin{array}{l}\text { A reportagem foi escrita por um jornalista. Apresenta o processo de construção histórico do } \\
\text { conhecimento abordado e sua relação com a sociedade. Indica uma ciência falível e com dados } \\
\text { controversos em algumas ocasiões. }\end{array}$ \\
\hline
\end{tabular}

Fonte: a pesquisa

A partir da análise do material, observou-se que os jornalistas se destacam na produção de textos publicados nestas edições, sendo 09 dos 24 textos produzidos por eles. Mas estes são seguidos de perto por grupos de pesquisadores, ou pelo menos dois deles, que dividem a autoria destas publicações, sendo 08 dos 24 textos. Os demais, 07 dos 24 textos, tem como autor um único pesquisador.

Um segundo item de análise está em como o conhecimento é visto e apresentado no texto. Assim, temos que este pode ser demonstrado como sendo produzido coletivamente, por uma equipe de trabalho e até mesmo dialogando com outras pesquisas, ou apresentado como 'verdades absolutas', onde não se faz referência ao seu contexto de produção. Deste modo, temos 16 dos 24 textos analisados introduzindo que o processo de construção do conhecimento se deu coletivamente. Já em 08 dos 24 textos, há indicações de 'verdades absolutas' em relação à maneira como o conhecimento é indicado no texto.

O último item a ser considerado nesta análise é visão de Ciência propriamente dita e, forma consideradas as seguintes categorizações: apresentação linear do conhecimento, se o conhecimento produzido é histórico ou não (ciência ahistórica ou pseudo-histórica), se apresenta uma imagem falível da Ciência, se induz à crença de 'gênios isolados', se no contexto de produção científica são indicadas controvérsias das pesquisas sobre um determinado tema e se existem indícios que os conhecimento produzidos são 'descobertas científicas'. Estas categorias não foram, em todos os casos, descritas em apenas um texto. Geralmente, aqueles que indicavam uma visão contrária àquelas apresentadas sobre $\mathrm{NdC}$, poderiam incorrer em mais de uma categoria. Sendo assim, observamos que: 
$\left.1^{\circ}\right)$ a relação histórica desta construção de conhecimentos está presente em 14 dos 24 textos. Já os outros 10 textos, indicam uma visão ahistórica ou pseudo-histórica do conhecimento científico. A seguir, expomos uma visão histórica desta produção;

Em 1979, antes de começar a minha pesquisa sobre a evolução dos avos, Milford H. Wolpoff, da University of Michigan, em Ann Arbor, publicou um artigo baseado em restos dentários, avaliando a idade dos neandertais de Krapina ao morrer. Os dentes molares irrompem em sequencia. Usando como guia um dos esquemas de erupção mais rápida observada no homem moderno, Wolpoff estimou que o primeiro, segundo e terceiro molares do homem de Neandertal surgiram em idades que se aproximavam dos 6, 12 e 15 anos, respectivamente. $O$ desgaste pela mastigação se acumula em ritmo constante ao longo da vida e por isso, quando surge o segundo molar, o primeiro já tem 6 anos de desgaste e, ao nascer o terceiro, o segundo tem três anos de desgaste. (Texto 2011_03).

$\left.2^{\circ}\right) 05$ dos 24 textos indicam uma linearidade do pensamento científico, como visto a seguir, num fragmento do texto 2010_04. "Esforços recentes de levantamento das espécies de peixes das cabeceiras do Tietê realizado pelos pesquisadores do Núcleo Integrado de Biotecnologia revelam novos dados em relação ao conhecimento da fauna da região";

$3^{\text {o })} 04$ textos indicam uma imagem de falibilidade da Ciência, enquanto 07 destes apresentam pesquisas controversas que auxiliaram a construção de uma visão científica mais real e condizente com a sociedade. A seguir, temos fragmentos do texto 2007_02 (falibilidade) e do texto 2010_01 (controvérsias), respectivamente;

\footnotetext{
"Os resultados são intrigantes”, comenta Kenneth Weiss, biólogo, antropólogo e geneticista da Pennsylvania State University. Ele observa que "se a propensão a ter gêmeos for genética, certamente há uma tendência seletiva, visando garantir a raridade dos casos. No entanto, alguns animais têm gêmeos rotineiramente". Sobre essa contradição, ele acrescenta, "ainda que a observação esteja correta, é arriscado superestimar os efeitos dessa característica. (Texto 2007_02).

Esse novo estudo determina que alguns ambientes de fontes hidrotermais são capazes de produzir pelo menos compostos orgânicos simples, possíveis ingredientes para a vida. Mas Lost City não é o local ideal para testar essas ideias, porque as torres de carbonato de cálcio não são reatores químicos estéreis. Na realidade, elas fervilham de vida micro biótica, o que levanta a possibilidade de esses micro-organismos estarem contribuindo para a formação de compostos orgânicos nos fluidos das chaminés. Para desvendar esse enigma, é preciso inspecionar os próprios micro-organismos mais de perto. (Texto 2010_01).
}

$4^{\circ}$ ) a ideia de 'descobertas científicas' e de 'gênios isolados' emergem de 09 e 03 textos, respectivamente. Assim, temos exemplos destes casos nos textos 2007_05 (descobertas) e 2009_3 (gênios isolados ou a ausência de demonstração trabalho em equipe e/ou diferentes grupos trabalhando o mesmo tema), como vemos, respectivamente nos fragmentos em seguida. 


\begin{abstract}
Meus colegas e eu agora estamos investigando a base molecular dessa habilidade, enquanto outros buscam descobrir como o órgão sensorial se forma durante o desenvolvimento, e se nossos próprios ancestrais vertebrados eram capazes de detectar campos elétricos antes de deixar o mar. Mas todo esse trabalho ainda é preliminar. Aqui descrevo como os pesquisadores descobriram a eletro-recepção nos tubarões e sua importância para uma caçada bem-sucedida.

Em um estudo com ácaro-rajado em morangueiro, no Estado de São Paulo, o Instituto Biológico (IB-APTA), órgão da Secretaria de Agricultura e Abastecimento do Estado de São Paulo, promoveu a liberação de ácaros predadores da espécie Neoseiulus californicus propiciando um bom controle da praga.
\end{abstract}

As visões equivocadas da Ciência podem ocorrer por diferentes meios informativos e formativos, que vão desde as interações sociais e familiares, passando por sua escolarização, e até mesmo, a consolidação desta a partir de seus contatos com os conhecimentos presentes em diversas mídias. Todo este conjunto pode ser capaz de gerar leitores com distorções acerca da Ciência que o rodeia. Segundo Briccia e Carvalho (2011, p. 02), diversos autores “também apontam que distorções sobre a ciência se encontram em diversos instrumentos de ensino, como em livros didáticos, textos, exercícios, questionários, entrevistas, entre outros”.

Mais uma vez iniciaremos esta argumentação a partir da construção textual por parte dos divulgadores, quer jornalistas quer cientistas. "Apesar da comunicação para esse tipo de público também ser realizada por cientistas, percebe-se que grande parte dos textos de divulgação tem sido elaborada por jornalistas havendo colaboração ou não de especialistas" (Nascimento, 2005, p. 04) e nisto encontramos coerência para os nossos resultados acerca da produção dos textos de DC.

Mesmo assim, grande parte dos divulgadores da Ciência se utiliza de uma subjetividade em relação ao seu posicionamento enquanto sujeito e escritor. Isso porque, geralmente,

nos textos científicos são utilizados elementos de construção que promovem o apagamento do sujeito no texto, enquanto ser ideologicamente constituído. Entretanto, esse apagamento é ilusório, pois o sujeito-autor - histórica e ideologicamente constituído - deixa no seu texto "pistas" que refletem sua presença enquanto sujeito que se inscreve no discurso (CUNHA e GIORDAN, 2009, p. 02).

Os autores/divulgadores, apesar dos esforços para fazerem valer o 'apagamento do sujeito', deixam traços de impressões sobre a visão de Ciência que julgam mais coerentes com seus próprios pensamentos, mesmo que implicitamente ou até inconscientemente. Por isso, Forato et al (2011, p. 36) comentam que

muitas vezes, as entrelinhas de um texto sugerem uma visão de Ciência diferente daquela que se busca defender. Algumas concepções arraigadas 


\section{Ensino, Saúde e Ambiente - V9 (3), pp. 171-188, Dez. 2016}

acabam por surgir furtivas em breves comentários ou adjetivos revelando juízos de valor que comprometem o resultado final de um trabalho, no que diz respeito às imagens de Ciência e seu funcionamento.

E assim, mesmo que não se dê conta, o autor já está subjetivamente indicando suas intencionalidades e as transferindo ao leitor. "Não é à toa que predomina em nossa sociedade uma imagem de ciência como um saber pautado em parâmetros de cientificidade das ciências exatas, biológicas e biomédicas: conhecimento acumulativo, sistematizável e atemporal" (ALFERES E AGUSTINI, 2008, p. 02). Deste modo, não devemos considerar somente as revistas de DC como os únicos meios para promoção destas visões sobre a Ciência.

De acordo com nossos resultados, a maioria dos textos analisados indica que os conhecimentos científicos estão sendo construídos coletivamente e, poucos são os que apresentam os conhecimentos como 'verdades absolutas'. Então, a princípio, os leitores teriam uma visão mais coerente da $\mathrm{NdC}$, mas isto não está totalmente de acordo com os dados da literatura já que, segundo Briccia e Carvalho (2011, p. 02), "muitos trabalhos demonstram que estudantes e até mesmo professores, independentemente do nível de atuação, possuem, em geral, concepções inadequadas sobre a ciência e sobre os cientistas".

Como visto em nossa introdução, os leitores não podem ser vistos ou tomados como indivíduos que não trazem nenhum conhecimento. Pelo contrário, devemos considerar previamente seus conhecimentos, ditos de senso comum sobre os mais diversos assuntos, para que a partir de então, se torne mais efetivo o processo de AC.

Até porque, combater visões não adequadas e tentar fazer com que estudantes e até mesmo professores possuam uma visão mais ampla do conhecimento científico faz parte também de um processo de $\mathrm{AC}$, no sentido de criar uma maior compreensão da $\mathrm{NdC}$ e dos fatores éticos e políticos que circundam sua prática (SASSERON e CARVALHO, 2008).

Para alguns autores, deve-se mudar este paradigma, do senso comum para o pensamento científico e de certa forma, apagar o pensamento anterior. Nisto, desconsidera-se esta 'bagagem' individual e pode ser que esta AC não seja consolidada, uma vez que os indivíduos possuem suas crenças, seus valores sociais e familiares e as mantém. Tais conhecimentos devem, portanto, ser construídos num processo gradual de AC. Para Briccia e Carvalho (2011, p. 05), “devemos também estar atentos para que 
nossos estudantes construam conhecimentos adequados sobre a Ciência, o que deve envolver um rompimento de concepções de senso comum".

Porém estes conhecimentos se tornarão efetivos quando houver a “desmistificação da Ciência enquanto 'assunto vedado aos não iniciados' para a ruptura com uma metodologia própria ao senso comum e às concepções espontâneas e, para, finalmente, estabelecer uma ponte para as primeiras modificações conceituais" (CASTRO E CARVALHO, 1992 apud BRICCIA e CARVALHO, 2011, p. 07).

Ainda, em nossos resultados sobre as visões de $\mathrm{NdC}$ presentes nos textos analisados, vimos que não há uma predominância enquanto a apresentação da historicidade da Ciência nos textos. Parte apresenta a História da Ciência dentro de um tema e outra parte, apresenta uma Ciência ahistórica ou pseudo-histórica. Assim temos uma visão de Ciência rígida, ahistórica por parte dos leitores.

Muito ligada a essa visão rígida, podemos mencionar a visão aproblemática
e ahistórica (portanto, dogmática e fechada): transmitem-se os
conhecimentos já elaborados, sem mostrar os problemas que lhe deram
origem, qual foi a sua evolução, as dificuldades encontradas etc., e não dando
igualmente a conhecer as limitações do conhecimento científico atual nem as
perspectivas que, entretanto, se abrem (GIL PÉREZ et al, 2001, p. 131).

Em algumas ocasiões, os textos se limitavam a apresentar um contexto histórico de produção do conhecimento científico como sendo "um tipo de calendário, repleto de datas, nomes e descobertas geniais. É fácil perceber que a imagem de ciência e de sua construção conflita diretamente com a visão perseguida como adequada pelas pesquisas em ensino de ciências" (FORATO et al, 2011, p. 39).

Quando no processo de AC se encontra arraigada a História da Ciência e, desta forma os leitores tem plenas condições de compreender melhor as características da $\mathrm{NdC}$, esta possui potencialidades de apresentar

\footnotetext{
uma ciência dinâmica e viva, discutindo-se a construção de um determinado conhecimento desde sua gênese até sua concepção atual, sem esquecer que este mesmo conhecimento pode estar sujeito a alterações futuras, concordando assim com a ideia de construção (MOREIRA E OSTERMANN, 1993 apud BRICCIA e CARVALHO, 2011, p. 07).
}

Um embasamento na História da Ciência para uma visão de $\mathrm{NdC}$ mais coerente é possível, já que esta pode "apresentar uma imagem menos utópica da Ciência e dos cientistas; gerar mais interesse pelo estudo da ciência; melhorar o clima e a participação no processo de ensino-aprendizagem" (SOLBES e TRAVER, 2001, p. 152).

Outros aspectos sobre a $\mathrm{NdC}$ também foram apresentados em nossos resultados. Vimos que, mesmo em uma pequena parte, alguns textos indicavam a 


\title{
Ensino, Saúde e Ambiente - V9 (3), pp. 171-188, Dez. 2016
}

construção do pensamento científico de forma linear. Isto se torna um problema à medida que renega as controvérsias geradas no meio científico e acadêmico para que aconteça a validação e a apropriação de um determinado conhecimento. Esta linearidade também é somada a poucos episódios ou aos mais marcantes historicamente sobre uma construção de um conhecimento científico.

Segundo Gil Pérez et al (2001, p. 132 e 133), esta deformação da Ciência é a segunda menos citada nos estudos realizados com os professores e essa visão deformada é, de certo modo, complementar da que denominamos visão rígida, embora devam ser diferenciadas: enquanto a visão rígida ou algorítmica se refere à forma como se concebe a realização de uma dada investigação, a visão acumulativa é uma interpretação simplista da evolução dos conhecimentos científicos, para a qual o ensino pode contribuir ao apresentar os conhecimentos hoje aceites sem mostrar como eles foram alcançados, não se referindo às frequentes confrontações entre teorias rivais, às controvérsias científicas, nem aos complexos processos de mudança.

Desta forma, também é passada uma imagem de Ciência sem controvérsias ou discussões sobre os temas já aceitos atualmente. Este é mais uma aspecto perigoso quando se pretende abordar a construção do pensamento e conhecimento científico durante um processo de AC. Isso porque demonstra uma Ciência sem conflitos ou já encerrada em suas ideias, onde

\begin{abstract}
tais narrativas trazem uma seleção apenas dos fatores que contribuem para uma reconstrução ordenada das etapas da criação de teorias e conceitos científicos aceitos pela ciência contemporânea. As ideias e os acontecimentos do passado são organizados como se o desenvolvimento da ciência seguisse etapas encadeadas logicamente, cujo resultado final seria fatalmente encontrado (FORATO et al, 2011, p. 38).
\end{abstract}

Então, não se abre espaço para o diálogo destas formações conceituais. Em contrapartida, deve-se ter cuidado ao apresentar tais controvérsias, uma vez que pode se tender a uma bipolarização entre teorias ditas rivais e enraizar um conceito de certo ou errado.

Recordemos, por exemplo, da forte oposição às concepções unitárias em Astronomia (heliocentrismo), em Biologia (evolucionismo) ou em Química Orgânica (síntese orgânica). Em todo caso, a desvalorização e mesmo o esquecimento dos processos de unificação como característica fundamental da evolução dos conhecimentos científicos constitui um verdadeiro obstáculo na educação científica habitual (GIL PÉREZ et al, 2001, p. 132).

O último item dos resultados sobre as visões de $\mathrm{NdC}$ presentes nos textos analisados, versa sobre a ideia de 'descobertas' realizadas, em muita ocasiões, por 'gênios isolados'. Essas são visões complementares, uma vez que, implicitamente, para 
validar o pensamento dos 'grandes gênios' são apresentados seus estudos e resultados de pesquisas como suas 'grandes descobertas'.

Segundo Gil Pérez et al (2001, p. 134) "parece razoável, por exemplo, que uma visão individualista e elitista da ciência apoie implicitamente a ideia empirista de "descoberta" e contribua, além do mais, para uma leitura descontextualizada e socialmente neutra da atividade científica". E assim, se consolidem no imaginário popular, quer do leitor, dos estudantes ou professores, duas visões distorcidas sobre todo processo de construção do conhecimento científico. "Assim, essas concepções aparecem associadas entre si, como expressão de uma imagem global ingênua da ciência que se foi decantando, passando a ser socialmente aceita" (GIL PÉREZ et al, 2001, p. 134).

Corre-se o risco de distanciar mais o estudante, leitor e cidadão da área científica, já que estas visões contribuem para um imaginário de cientista/pesquisador solitário, isolado socialmente e neutro em seus posicionamentos. Ainda reforça a ideia de Ciência feita e direcionada a uma elite intelectual, composta por 'mentes brilhantes' que são privilegiadas socialmente e em seu acesso à educação. Mais uma vez, arrisca-se o próprio pensar e fazer científico, pois através de 'descobertas', o trabalho não parece tão árduo e seus resultados surgem quase como acontecimentos ao acaso. Uma pequena parte pode até ser assim, mas não o todo. O trecho a seguir representa bem esta argumentação.

\footnotetext{
Muitas vezes insiste-se explicitamente em que o trabalho científico é um domínio reservado a minorias especialmente dotadas, transmitindo-se assim expectativas negativas à maioria dos alunos, com claras discriminações de natureza social e sexual (a ciência é apresentada como uma atividade eminentemente "masculina"). Contribui-se, além do mais, para esse elitismo escondendo o significado dos conhecimentos por meio de apresentações exclusivamente operativas. Não se faz um esforço para tornar a ciência acessível (começando com tratamentos qualitativos, significativos), nem para mostrar o seu carácter de construção humana, em que não faltam hesitações nem erros, situações semelhantes às dos próprios alunos (GIL PÉREZ et al, 2001, p. 133).
}

Portanto, para se assumir visões menos ingênuas e mais coerentes sobre o fazer científico e em relação a própria estrutura da Ciência, deve-se considerar esta "como um empreendimento humano, mediante a compreensão da construção sócio histórica do conhecimento, articulando conteúdos científicos, históricos e da abordagem explícita da NdC" (FORATO et al, 2011, p. 53). 
Ensino, Saúde e Ambiente - V9 (3), pp. 171-188, Dez. 2016

\section{CONCLUSÃO}

Quanto aos aspectos relacionados à Natureza da Ciência $(\mathrm{NdC})$, temos a ideia de que há uma construção coletiva dos conhecimentos apresentados e poucos conhecimentos são apresentados como 'verdades absolutas'. Assim, este item se torna positivo dentro do contexto da revista Scientific American Brasil, pois demonstra uma preocupação, em identificar ao leitor como tal conhecimento que está apresentado em um determinado texto foi elaborado. Isso também desconstrói esta distorção sobre uma Ciência absoluta em suas verdades e quase dogmática.

Em relação à apresentação dos conhecimentos como construção histórica, temse que parcialmente há esta visão histórica e crítica e a outra parte, se baseia em pseudohistórica ou ahistórica, sendo que poucos textos (respectivamente 05 e 04 deles) apresentaram a ideia de uma Ciência linear e falível, o que se torna contraditório com o quadro teórico introdutório e alguns textos (09 deles) indicam a ideia de 'descobertas científicas', enquanto 03 deles, apresentam o ideal de 'gênios da Ciência'.

\section{REFERÊNCIAS BIBLIOGRÁFICAS}

ACEVEDO-DÍAZ, J.A., VÁZQUEZ-ALONSO, PAIXÃO, M.F., ACEVEDOROMERO A., OLIVA, J.M. e MANASSETRO-MAS, M.A. Mitos da didática das Ciências acerca dos motivos para incluir a Natureza da Ciência no Ensino das Ciências. Ciência \& Educação, v. 11, n. 1, p. 1-15, 2005.

ALBAGLI, S. Divulgação científica: informação científica para a cidadania? Ci. Inf., Brasília, v. 25, n. 3, p.396-404, 1996.

ALFERES, S.C.; AGUSTINI, C.L.H. A escrita da Divulgação Científica. Relatório final apresentado à Pró-Reitoria de Pesquisa da UFU, Uberlândia, MG: Universidade Federal de Uberlândia 2008.

ALMEIDA, A.V.; DA ROCHA FALCÃO, J.T. A estrutura histórico-conceitual dos programas de pesquisa de Darwin e Lamarck e sua transposição para o ambiente escolar. Ciência \& Educação, v. 11, n. 1, p. 17-32, 2005.

BARDIN, L. Análise de Conteúdo. Tradução: Luís Antero Reto e Augusto Pinheiro. Lisboa: Edições 70, 1977.

BRICCIA, V.; CARVALHO, A.M.P. Visões sobre a natureza da ciência construídas a partir do uso de um texto histórico na escola média. Revista Electrónica de Enseñanza de las Ciencias, v.10, n.01, p.1-22, 2011.

CERQUEIRA, A.V. Representações sociais de dois grupos de professores de Biologia sobre o ensino de Origem da Vida e Evolução Biológica: aspirações, ambiguidades e demandas profissionais. 2009. 90p. Dissertação (Mestrado em Ensino de Ciências e Saúde) - Universidade Federal do Rio de Janeiro, Rio de Janeiro, 2009. CUNHA, M.B.; GIORDAN, M. A Divulgação Científica como um gênero de discurso: implicações na sala de aula. In: VII ENPEC (Encontro Nacional de Pesquisa em Educação em Ciências). 2009.

EPSTEIN, I. Divulgação científica: 96 verbetes. Campinas: Pontes, 2002. 
FORATO, T.C.M., PIETROCOLA, M. E MARTINS, R.A. Historiografia e Natureza da Ciência na sala de aula. Cad. Bras. Ens. Fís., v. 28, n. 1, p. 27-59, 2011.

GIL PÉREZ, D.; MONTORO, I.F.; ALÍS, J.C.; CACHAPUZ, A.; PRAIA, J. Para uma imagem não deformada do trabalho científico. Ciência \& Educação, v.7, n. 02, p.125153, 2001.

GOMES, R. A análise de dados em pesquisa qualitativa. In: MINAYO, M. C. de S. (org). Pesquisa Social: teoria, método e criatividade. 14ª ed. Petrópolis: Vozes, 1999. IZQUIERDO, I. Aumentando o conhecimento popular sobre a Ciência. In: Seminários temáticos para a $3^{\text {a }}$ Conferência Nacional de Ciência, Tecnologia e Inovação. Parcerias estratégicas, pp. 1-554, Brasília, DF, Brasil, 2005.

KEMPER, A. A Evolução Biológica e as Revistas de Divulgação Científica: Potencialidades e limitação para o uso em sala de aula. 2008. 152p. Dissertação (Mestrado em Educação) - Universidade de Brasília, Brasília, 2008.

MACEDO, M.G. Do texto ao hipertexto: argumentação e legibilidade nos discursos da divulgação científica. 2002. 305 p. Tese de Doutorado em Comunicação - UNESP, São Paulo, 2002.

MOREIRA, I.C.; MASSARANI, L. Aspectos históricos da Divulgação Científica no Brasil. In: Ciência e público: caminhos da divulgação científica no Brasil. Luisa Massarani, Ildeu de Castro Moreira e Fatima Brito (org). Rio de Janeiro: Casa da Ciência - Centro Cultural de Ciência e Tecnologia da Universidade Federal do Rio de Janeiro. Fórum de Ciência e Cultura. 2002.

MORTIMER, E.F. Construtivismo, mudança conceitual e Ensino de Ciências: para onde vamos? Investigações em Ensino de Ciências, v1, n.1, p.20-39, 1996.

NASCIMENTO, T.G. Contribuições da Análise do Discurso e da epistemologia de Fleck para a compreensão da Divulgação Científica e sua introdução em aulas de Ciências. Revista Ensaio, v. 01, n. 02, p. 1-18, 2005.

PETIAN, C., COSTA, M. e TREVISAN, R. Scientific American Brasil e Superinteressante: uma análise comparativa do discurso científico no conteúdo dos dois veículos, 2006.

Disponível em: http://www.metodista.br/ev/congresso/programacao-cursos/posgraduacao-em-comunicacao-social. Acesso em: 03 de abril de 2012.

PRAIA, J., GIL-PÉREZ, D.; VILCHES, A. O papel da Natureza da Ciência na Educação para a Cidadania. Ciência \& Educação, v. 13, n. 2, p. 141-156, 2007.

SANTOS, W.L.P., Educação Científica na perspectiva de letramento como prática social: funções, princípios e desafios. Revista Brasileira de Educação, v. 12, n. 36, p. 474-550, 2007.

SASSERON, L.H.; CARVALHO, A.M.P. Almejando a Alfabetização Científica no Ensino Fundamental: A Proposição e a procura de indicadores do processo.

Investigações em Ensino de Ciências, v. 13, n.3, p.333-352, 2008.

SASSERON, L.H; CARVALHO, A.M.P. Alfabetização Científica: uma revisão bibliográfica. Investigações em Ensino de Ciências, v. 16, n. 1, p. 59-77, 2011. SOLBES, J.; TRAVER, M. Resultados obtenidos introduciendo Historia de la Ciencia en las clases de física y química: mejora de la imagen de la Ciencia y desarrollo de actitudes positivas. Enseñanza de las Ciencias, v. 19, n.1, p. 151-162, 2001. VILLANI, A. Filosofia da Ciência e Ensino de Ciência: uma analogia. Ciência \& Educação, v.7, n. 02, p.169-181, 2001. 